\title{
Effective Clinical Teaching Practice and Associated Factors among Midwifery Educators in Public Universities of Ethiopia, 2019
}

Kebenesa Angasu Kitaba ( $\square$ kebenesa2019@gmail.com )

Jimma University https://orcid.org/0000-0003-0354-4161

Solomon Weldemariam Gebrehiwot

Mekelle University College of Health Sciences Department of Midwifery

Abate Bekele Belachew

Mekelle University College of Health Sciences School of Public Health Department of Biostatistics

Research article

Keywords: Effective clinical teaching, associated factors, Midwifery educators, Ethiopia

Posted Date: August 26th, 2019

DOI: https://doi.org/10.21203/rs.2.13569/v1

License: (c) (i) This work is licensed under a Creative Commons Attribution 4.0 International License.

Read Full License 


\section{Abstract}

Abstract Background: Despite the fact that effective clinical teaching realistically enhances learners to be competent, in Ethiopia only $31.6 \%$ of midwifery graduates passed the national standard of competence for graduation in 2013. Likewise, evidence is lacking on effective clinical teaching practice of midwifery educators in Ethiopia. As a result, this study aimed to assess effective clinical teaching practice and associated factors among midwifery educators in Public Universities of Ethiopia. Methods: Institution based cross-sectional study was conducted among midwifery educators in Ethiopia in April, 2019. A total of 424 educators were randomly selected to participate in this study. Data were collected through email then entered into Epi-data version 3.1 and transported to SPSS version 23 for analysis. The data presented using frequency, percentage and tables. Multivariable logistic regression analysis was done to identify associated factors of effective clinical teaching practice. The odds ratio at $95 \%$ confidence interval used to ascertain association. Statistical significance declared at $P<0.05$. Results: Only $178(47.3 \%)$ of participants had effective clinical teaching practice. Clinical teaching experience (AOR= $4.72 ; 95 \% \mathrm{Cl}=1.97,11.29)$, training on higher diploma in teaching profession ( $\mathrm{AOR}=2.78 ; 95 \% \mathrm{Cl}=1.61$, 4.82), clinical teaching workshop ( $A O R=4 ; 95 \% \mathrm{Cl}=1.98,8.05)$, students per clinical unit $(A O R=3.71$; $95 \% \mathrm{Cl}=1.66,8.26)$, giving objectives of clinical learning for students ( $\mathrm{AOR}=4.74 ; 95 \% \mathrm{Cl}=2.43,9.25)$, using performance based assessment tool $(A O R=1.82 ; 95 \% \mathrm{Cl}=1.04,3.16)$ and having good interest in clinical teaching $(A O R=8.63 ; 95 \% \mathrm{Cl}=2.91,25.56)$ were factors positively associated with effective clinical teaching practice. Conclusions: Less than half of midwifery educators of Ethiopian Public Universities had effective clinical teaching practice. The educators' clinical teaching experience, training and adhering to clinical teaching standards were identified to affect effective clinical teaching positively. Therefore, the educators should adhere to the standards for effective clinical teaching and receive trainings on effective teaching. Key words: Effective clinical teaching, associated factors, Midwifery educators, Ethiopia

\section{Background}

Midwifery is a profession concerned with provision of holistic care for women during maternal life, for newborn, and infants (1). Ability to perform midwifery competency in real situation can't be achieved through classroom learning alone (2). Thus, the preponderance of clinical experience in the training of midwifery students cannot be undervalued. It is noteworthy in guiding midwifery education process (3). To enable midwifery students acquire intended clinical experience, effective clinical teaching (ECT) is compulsory (4). But the quality and competence of midwifery graduate is affected by the excellence and capability of midwifery educators to teach effectively (5).

Midwifery educator has obligation to deliver ECT that optimally facilitate students' learning (6). These include consistently performing ECT attributes such as establishing rapport with learners, and maximizing the use of case-based learning opportunities (7), being knowledgeable, providing support, role modeling, being clinically competent, knowing how to teach and being communicative $(6,8,9)$. ECT build students' clinical knowledge, skill, attitude, critical thinking, clinical judgment and decision making ability (4). Accordingly, ECT can lead to the fulfillment of the $5^{\text {th }}$ Ethiopian educational sector 
development plan for educational relevance and quality improvement in midwifery context. Which is to produce demand-driven and competent midwifery graduates (10).

Ethiopia is a developing country committed at expanding equitable access to quality tertiary education $(10-12)$. But the graduation rate of students by first degree from university is as low as $79 \%$ partly due to low quality of instruction (10). Even among midwifery diploma and first degree graduates, only $31.6 \%$ passed the national standard ( $\geq 60 \%$ ) of competence for graduation in 2013 after examined at the point of their graduation which leads to failure to satisfy country's demand for competent and qualified midwifery professional (13).

Related studies done previously were focused on describing how frequently each effective clinical teaching attributes were implemented by clinical educators (4,14-16). In addition, none of these studies identified factors associated with effective clinical teaching practice (ECTP). However, the current study was aimed to identify factors associated with ECTP using regression analysis. Hence, the findings contribute new knowledge on ECTP among midwifery educators in public universities of Ethiopia. In addition, it helps midwifery educators to maximize ECTP and so does the competency of midwifery graduates that can satisfy the country's demand for competent midwifery professional. Moreover, it establishes baseline information for further study. Lastly, it serves as springboard for stakeholders to deal with the problem.

\section{Methods}

\section{Study area, period and design}

Institution based cross-sectional study was conducted in 30 Ethiopian Public Universities (EPU) in April, 2019. These universities were selected because they have at least Bachelor of Science degree in midwifery education regular program (BScMERP) and have started teaching clinical courses. In Ethiopia, there are 47 public universities distributed in all 11 regional states of the country. The 30 EPU with BScMERP had 807 midwifery educators of whom 584 of them are male. At the data collection period, 502 midwifery educators were active staffs while the rest 279 were learning their master's degree and 26 were learning their PhD degree.

\section{Study population and sampling procedures}

The study population was all midwifery educators who were working in 30 EPU which have BScMERP. Midwifery educators recruited as regular academic staff in the 30 EPU for position of graduate assistant Il and above and who taught at least 1 clinical course within this (2018/2019) and/or last (2017/2018) academic year were eligible for this study. Midwifery educators who were learning their master's degree or $\mathrm{PhD}$ were excluded from this study since they are on education hence their response could probably be the result of the education they are learning but may not be what they actually practice during their 
clinical teaching. On the other hand, since they might be busy on their study, the concern they give for such extra responsibility may be low and may not provide their response.

The sample size was calculated using single population proportion formula $\left(n=(z a / 2)^{2} p(1-p) / d^{2}\right)$ with the assumption of (50\%) proportion of ECTP, $95 \%$ confidence level, $5 \%$ level of precision and $10 \%$ of nonresponse rate resulting 424 sample size. Simple random sampling technique was used to select study participants. The sample size was proportionally allocated for the 30 EPU using the sampling frame taken from the midwifery department of respective universities.

\section{Data collection tool, procedures and quality assurance}

Data collection tool was semi-structured questionnaire partially developed incorporating both locally relevant factors those were not studied previously and factors identified by different studies conducted elsewhere (17-20). In addition, it was partially adopted from clinical teachers effectiveness inventory tool developed by Mogan \& Knox and cited in Marcia (14).The questionnaire was developed in English and did not translated to local language as respondents were university midwifery educators and they were considered as they understand English as it is the official working language at university level in the country. Pretest was done on $43(10 \%)$ of the sample size among nurse educators of Jimma University before the actual study. The purpose of the pretest was to test validity and reliability of the questionnaire and to check the wording, logic and order of the questions. Finally, the questionnaire was found valid and reliable with Cronbach alpha coefficient 0.88 which shows good internal consistency and modification was made concerning the syntax of the questionnaire accordingly.

ECTP was defined as practicing qualities that enable clinical educators to teach effectively. These qualities include being knowledgeable, clinically competent, skillful in clinical teaching and evaluation of clinical learning of students, interpersonal relationships with students, and personal characteristics of clinical educator those facilitate clinical learning of students. ECTP was measured using 47 items that describe qualities that enable clinical educators to teach effectively using 1-5 points. Sum of the score was used to classify the status of ECTP of respondents using $75 \%$ as cut point as EPU use it as criteria for effective teaching. As an example the legislation of Jimma University was referenced (21). As a result, respondents those had sum of score $\geq 188(75 \%)$ were considered as having ECTP and those had sum of score $<188(75 \%)$ were considered as having not ECTP.

Data were collected through email. To assure quality of data, pretested, valid and reliable questionnaire was used to collect data. Objective of the study was clarified for participants and confidentiality of their response was assured to encourage them to provide their genuine response. Questionnaires with unfilled and/or inconsistent part were sent back to respective respondents and made to be corrected and sent back again for the principal investigator.

\section{Data processing and analysis}


The collected data were checked for completeness, coded and entered into Epi-data version 3.1 and exported to SPSS version 23 for data processing and analysis. Data cleaning was performed using frequencies, sorting, and listing to see missed values and outliers and then correction was made accordingly. Descriptive statistics such as frequency and percentages were used to describe the study participants. Multivariable logistic regression analysis was done to identify associated factors of ECTP. Odds ratio with $95 \%$ confidence interval was estimated to measure the strength of association between independent and outcome variable. Variables that have $p$-value of $<0.2$ at bivariate analysis were included in multivariable logistic regression to control possible confounding factors. Statistical tests at $p$ value of $<0.05$ were considered as cut off point to determine statistical significance. Forward stepwise likelihood ratio method of analysis was used to develop final model due to large number of independent variables that did not allow to use the enter method. Multicollinearity was tested using variance inflation factor (VIF) and it was indicating absence of significant co-linearity (all less than ten). Hosmer and Lemeshow model fitness chi-square test was 6.569 and p-value was non-significant (0.58) indicating the model was good in fitting the data.

\section{Ethical consideration}

Ethical approval was obtained from the institutional ethical review board of Mekelle University College of Health Sciences with protocol number: ERC 1243/2019. Support letter was obtained from department of midwifery. Both ethical approval and support letter was submitted to respective head midwifery department of the $30 \mathrm{EPU}$. Each study subjects were informed about the purpose, benefit, risk, confidentiality of their response through information provided on participant information sheet and written informed consent was obtained.

\section{Results}

\section{Socio-demographic characteristics of respondents}

In this study, 376 midwifery educators were participated making a response rate of $88.7 \%$. Around fourfifth $298(79.3 \%)$ of respondents were male. While the median age was 30 with interquartile range (the first and third quartiles) was 27 and 32 years, respectively (Table 1).

\section{In-service training status of respondents}

Just more than three-fourth 292(77.7\%), two-fifth 161(42.8\%), and one-fourth $97(25.8 \%)$ of respondents were trained on basic effective teaching skill, trained on higher diploma in teaching profession (HDP) and had clinical teaching workshop respectively. But, nearly all $367(97.6 \%)$ of respondents were not trained on training of trainers of effective teaching skill. 


\section{Clinical teaching site characteristics}

More than two-fifth 166(44.2\%) of respondents teach clinical courses where students were learning in same clinical teaching site at the same time from five (midwifery, nurse, public health officer, pharmacy and medicine) departments (Table 2).

\section{Faculty characteristics}

Near to two-third $241(64.1 \%)$ of respondents give students objective of clinical teaching for every clinical teaching session in written form. In addition, more than half $209(55.6 \%)$ of respondents had classroom teaching as additional workload during their clinical teaching. Similarly, around two-fifth $156(41.5 \%)$ of respondents use performance based assessment tool for assessing students' clinical learning objectively. In contrast less than one-fifth $67(17.8 \%)$ of respondents use guideline for clinical teaching.

\section{Self-reported attributes of respondents toward clinical teaching}

Respondents' attribute toward clinical teaching was measured by single item using 5-point likert scale indicating 1-very poor, 2-poor, 3-fair, 4-good, and 5-very good. As a result, there was no response as very poor and poor. Then response with good and very good was condensed as good and response with fair was kept as it was. In general, most 345(91.8\%), 298(79.3\%), 311(82.7\%), 316(84\%), and 334(88.8\%) of respondents reported that they had good interest in midwifery profession, had good midwifery curriculum knowledge competency, had good midwifery skill competency, had good interest in clinical teaching, and had good communication skill respectively.

\section{Effective clinical teaching practice and factors associated with it}

More than half 198(52.7\%) of respondents had not ECTP. From multivariable binary logistic regression analysis seven variables were statistically significantly associated with ECTP. Those variables were clinical teaching experience, training on HDP, clinical teaching workshop, number of students per clinical unit, provision of clinical learning objective of clinical teaching for every clinical teaching session in written form, using performance based assessment tool for assessing students' clinical learning objectively, and interest in clinical teaching.

The odds of ECTP among midwifery educators those had 1-3 and 4-6 years of experience in clinical teaching was 3.31 and 4.72 times higher respectively compared to midwifery educators those had $\leq 1$ year of clinical teaching experience $(A O R=3.31 ; 95 \% \mathrm{Cl}=1.46,7.44) \&(A O R=4.72 ; 95 \% \mathrm{Cl}=1.97,11.29)$. 
Similarly, the odds of ECTP among midwifery educators those were trained on HDP was 2.78 times higher compared to their counterpart (AOR $2.78 ; 95 \% \mathrm{Cl}=1.61,4.82$ ).

The odds of ECTP among midwifery educators who had clinical teaching workshop was 4 times higher compared to midwifery educators who did not have clinical teaching workshop $(A O R=4 ; 95 \% \mathrm{Cl}=1.98$, 8.1). In addition, the odds of ECTP among midwifery educators those teach 5-8 and 9-12 students per clinical unit was 3.71 and 2.39 times higher respectively compared to midwifery educators those teach $\geq 13$ students per clinical unit $(\mathrm{AOR} 3.71 ; 95 \% \mathrm{Cl}=1.664,8.265)$ at $(\mathrm{p}$-value $=.001) \&(\mathrm{AOR} 2.39 ; 95 \% \mathrm{Cl}=$ $1.26,4.54)$.

Moreover, the odds of ECTP among midwifery educators those provide objective of clinical learning in written form to students for every clinical teaching session was 4.74 times higher compared to midwifery educators those did not provide it for students (AOR $4.74 ; 95 \% \mathrm{Cl}=2.43,9.26$ ). Furthermore, the odds of ECTP among midwifery educators those use performance based assessment tool for assessment of clinical learning of students' was $82 \%$ higher compared to those did not use it to assess clinical learning of students (AOR 1.82; $95 \% \mathrm{Cl}=1.05,3.16$ ) Lastly, the odds of ECTP among midwifery educators those had good interest in clinical teaching was 8.63 times higher compared to midwifery educators those had fair interest in clinical teaching (AOR 8.63; $95 \% \mathrm{Cl}=2.91,25.56)$ (Table 3$)$.

\section{Table 1. Socio-demographic characteristics of midwifery educators of Ethiopian Public Universities, Ethiopia, 2019, ( $N=376)$}




\begin{tabular}{|c|c|c|c|}
\hline Variables & Category & Frequency & $\begin{array}{l}\text { Percent } \\
\text { (\%) }\end{array}$ \\
\hline \multirow[t]{3}{*}{ Age in years } & $</=24$ & 21 & 5.6 \\
\hline & $25-34$ & 323 & 85.9 \\
\hline & $>/=35$ & 32 & 8.5 \\
\hline \multirow[t]{2}{*}{ Marital status } & Married & 263 & 69.9 \\
\hline & Single & 113 & 30.1 \\
\hline \multirow[t]{2}{*}{ Professional qualification } & BSc & 98 & 26.1 \\
\hline & MSc & 278 & 73.9 \\
\hline Clinical experience before becoming academic & None & 148 & 39.4 \\
\hline \multirow[t]{2}{*}{ staff (in years) } & $<2$ & 82 & 21.8 \\
\hline & $\geq 2$ & 146 & 38.8 \\
\hline \multirow[t]{4}{*}{ Clinical teaching experience (in years) } & $</=1$ & 81 & 21.5 \\
\hline & $1-3$ & 160 & 42.6 \\
\hline & 4- 6 & 119 & 31.6 \\
\hline & $>6$ & 16 & 4.3 \\
\hline \multirow[t]{3}{*}{ Sum of clinical courses ever taught } & $</=5$ & 140 & 37.2 \\
\hline & $6-10$ & 144 & 38.3 \\
\hline & $\geq 11$ & 92 & 24.5 \\
\hline
\end{tabular}

Table 2 Clinical teaching site characteristics where midwifery educators of Ethiopian Public Universities teach clinical courses, Ethiopia, 2019, ( $\mathrm{N}=376)$ 
Clinical teaching site

General and primary 29

hospital

Teaching, general \& or 122

primary hospital

All public hospitals \& health 201

center

public and private hospital \& 24

health center

Number of students per clinical unit $\quad<4$

$>/=13$

Coordination between theoretical Relevant theoretical fully 309 and clinical teaching covered

Only some theoretical 57

teaching covered

$\begin{array}{lllll}\text { No appropriate case for } & 10 & 2.6\end{array}$

theory covered

Availability of necessary resource

All adequately available

19

5 for clinical teaching

Only some adequately 104

available

Some available but not 253

67.3 adequate

\section{Table 3.Bivariate and multivariable analysis of factors associated with effective clinical teaching practice among midwifery educators of Ethiopian Public Universities, Ethiopia, 2019, ( $N=376)$}




\begin{tabular}{|c|c|c|c|c|c|c|}
\hline \multirow[t]{2}{*}{ Variables } & \multirow[t]{2}{*}{ Category } & \multicolumn{2}{|l|}{ ECTP } & \multirow[t]{2}{*}{ COR(95\%CI) } & \multirow[t]{2}{*}{ AOR(95\%CI) } & \multirow{2}{*}{$\begin{array}{l}\mathrm{P} \text { - } \\
\text { value }\end{array}$} \\
\hline & & $\begin{array}{l}\text { No } \\
\%)\end{array}$ & $\begin{array}{l}\text { Yes (N, } \\
\%)\end{array}$ & & & \\
\hline \multirow{4}{*}{$\begin{array}{l}\text { Experience in } \\
\text { clinical teaching } \\
\text { (in years) }\end{array}$} & $\leq 1$ & $66(81.5)$ & $15(18.5)$ & 1 & 1 & \\
\hline & $1-3$ & $86(53.7)$ & $74(46.3)$ & $\begin{array}{l}3.79(1.99 \\
7.19)\end{array}$ & $\begin{array}{l}3.31(1.47, \\
7.44)\end{array}$ & .004 \\
\hline & $4-6$ & $41(34.5)$ & $78(65.5)$ & $\begin{array}{l}8.37(4.26 \\
16.46)\end{array}$ & $\begin{array}{l}4.72(1.97 \\
11.29)\end{array}$ & .000 \\
\hline & $>6$ & $5(31.3)$ & $11(68.7)$ & $\begin{array}{l}9.68(2.93, \\
32.03)\end{array}$ & $\begin{array}{l}3.68(.79 \\
17.19)\end{array}$ & .098 \\
\hline \multirow[t]{2}{*}{ Trained on HDP } & No & $150(69.8)$ & $65(30.2)$ & 1 & 1 & \\
\hline & Yes & $48(29.8)$ & $113(70.2)$ & $\begin{array}{l}5.43(3.48, \\
8.48)\end{array}$ & $\begin{array}{l}2.78(1.61, \\
4.82)\end{array}$ & .000 \\
\hline \multirow{2}{*}{$\begin{array}{l}\text { Attended clinical } \\
\text { workshop }\end{array}$} & No & $176(63.1)$ & $103(36.9)$ & 1 & 1 & \\
\hline & Yes & $22(22.7)$ & $75(77.3)$ & $\begin{array}{l}5.83(3.42, \\
9.93)\end{array}$ & $4(1.98,8.05)$ & .000 \\
\hline \multirow{4}{*}{$\begin{array}{l}\text { Student } \\
\text { clinical unit }\end{array}$} & $\leq 4$ & $13(68.4)$ & $6(31.6)$ & $\begin{array}{l}.69(.25 \\
1.92)\end{array}$ & $\begin{array}{l}1.15(.33 \\
4.08)\end{array}$ & .827 \\
\hline & $5-8$ & $21(33.3)$ & $42(66.7)$ & $\begin{array}{l}3(1.62 \\
5.56)\end{array}$ & $\begin{array}{l}3.71(1.66, \\
8.27)\end{array}$ & .001 \\
\hline & $9-12$ & $74(51.4)$ & $70(48.6)$ & $\begin{array}{l}1.42(.89 \\
2.25)\end{array}$ & $\begin{array}{l}2.39(1.26 \\
4.54)\end{array}$ & .008 \\
\hline & $\geq 13$ & $90(60)$ & $60(40)$ & 1 & 1 & \\
\hline \multirow{2}{*}{$\begin{array}{l}\text { Provide CLO for } \\
\text { students }\end{array}$} & No & $84(62.2)$ & $51(37.8)$ & 1 & 1 & \\
\hline & Yes & $114(47.3)$ & $127(52.7)$ & $\begin{array}{l}1.84(1.19, \\
2.82)\end{array}$ & $\begin{array}{l}4.74(2.43, \\
9.26)\end{array}$ & .000 \\
\hline \multirow[t]{2}{*}{ Using PBA tool } & No & $135(61.4)$ & $85(38.6)$ & 1 & 1 & \\
\hline & Yes & $63(40.4)$ & 93(59.6) & $\begin{array}{l}2.34(1.54, \\
3.57)\end{array}$ & $\begin{array}{l}1.82(1.05 \\
3.16)\end{array}$ & .034 \\
\hline \multirow{2}{*}{$\begin{array}{l}\text { Interest in clinical } \\
\text { teaching }\end{array}$} & Fair & $55(91.7)$ & $5(8.3)$ & 1 & 1 & \\
\hline & Good & $143(45.3)$ & $173(54.7)$ & $\begin{array}{l}\text { 13.31(5.19, } \\
34.13)\end{array}$ & $\begin{array}{l}8.63(2.91, \\
25.56)\end{array}$ & .000 \\
\hline
\end{tabular}

\section{Discussion}

This study found that less than half $178(47.3 \%)$ of midwifery educators of Ethiopian Public Universities had effective clinical teaching practice. Clinical teaching workshop, training on HDP, clinical teaching experience, number of students a clinical educator teach per clinical unit, using performance based assessment tool for assessing clinical learning of students, provision of objective of clinical learning in 
written form to students for every clinical teaching session, and interest in clinical teaching were found to be factors associated with effective clinical teaching practice.

In the current study, years of experience in clinical teaching was found to be positively associated with ECTP. This result is consistent with the result of study done in six Universities of North America where effect of teacher experience on improving ECTP was strongest during the first few years of teaching (19). Similarly, in the current study, training on higher diploma in teaching profession and clinical teaching were found to promote provision of ECTP. This finding is consistent with the result of study done in Malaysia where in-service training had improved ECTP by empowering teachers to be systematic and logical (17).

In addition, the current study showed that class size per clinical teaching unit is positively associated with ECTP. This result is consistent with the result of study done at Department of Midwifery in Mekelle University that suggested 5-8 students per clinical unit to effectively provide clinical education(22). It is also in-line with the result of study done at Oman Nursing College that suggested 4 students per clinical teaching unit to maximize ECTP (9).

Moreover, the current study revealed that provision of objective of clinical learning in written form to students for every clinical teaching session promoted the ECTP. This finding is consistent with the existing knowledge that clinical educator should give to students clinical competencies for every clinical teaching session in written form and should clarify it for students until they clearly understood it to foster $\operatorname{ECTP}(7)$.

The current study showed using performance based assessment tool for assessment of clinical learning of students' increased the chance of ECTP by educators. This finding is consistent with the result of study done in Iran at Guilan University where using clear evaluation system affected effective clinical teaching practice by $62.1 \%$ (18). Possibly because educators who use performance based assessment tool probably make their teaching approach in-line with what students were going to be assessed on and also student themselves may stimulate the educators to teach them focusing on what they were going to be assessed on. In addition, using performance based assessment tool allows identifying students' area of weakness and strength that would enable clinical educators to align their teaching approach with students' level of readiness that would enable them to practice effective clinical teaching.

Midwifery educators' interest in clinical teaching was found to increase the chance of ECTP by clinical educators. This finding is consistent with the finding of study done at Guilan University in Iran where interest in clinical teaching affected ECTP by $93.9 \%$ (18). This finding might indicate that interest in clinical teaching affects ECTP as it is universal that without having interest it is impossible to achieve whatever is needed to be achieved (23).

\section{Strengths And Limitation}


This study was conducted at national level using large sample size and probability sampling method to minimize selection bias and to ensure its generalizability. To minimize information bias pretested, valid and reliable questionnaire was used to collect data. Study participants were also limited using exclusion criteria to those who were on clinical practice at data collection period to reduce recall bias. Similarly, the objective of the study was clearly described for study participants and confidentiality of their response were assured to enable participants to be free of fear of social desirability bias and to encourage them to provide their genuine response. In addition, data quality was maintained throughout and appropriate statistical analysis method was used with strong model goodness of fit test. However, it was not without limitation. It was better to support the finding of this study by data collected by observational method to further strengthen the validity of the findings.

\section{Conclusions}

Less than half of midwifery educators of Ethiopian Public Universities had effective clinical teaching practice. Several factors were found to have effect on ECTP among Ethiopian midwifery educators. Clinical teaching experience, training on higher diploma in teaching profession, attaining clinical teaching workshop, number of students a clinical educator teach per clinical unit, providing objectives of clinical learning in written form to students for every clinical teaching session, using performance based assessment tool for assessing students' clinical learning and interest in clinical teaching of educators were positively associated with ECTP. Therefore, the higher diploma program and clinical trainings for educators should to be strengthened in order to deliver the clinical education effectively and efficiently. In addition, the educators and the department should adhere to the guide for ECTP such as limiting the class size to the standard for provision of effective clinical teaching.

\section{Abbreviations}

BScMERP: Bachelor of Science Degree in Midwifery education regular program; ECT: Effective Clinical Teaching; ECTP: Effective Clinical Teaching Practice; EPU: Ethiopian Public Universities; HDP: Higher Diploma Program.

\section{Declarations}

\section{Acknowledgements}

The authors are very grateful to Mekelle University for the financial support to this study and Department of Midwifery for its mentorship. We are also thankful to the study participants for their willingness and commitment to participate in this study.

\section{Funding}


This study was done by fund provided by Mekelle University merely for data collection purpose as for MSc thesis.

\section{Authors' contributions}

KA designed the study, prepared the proposal, obtained funding and data, analyzed and interpreted the data and prepared this manuscript. SWG and ABB had provided guidance to the corresponding author throughout the course of the study, reviewed the paper from beginning to end and approved the manuscript for publication.

\section{Competing interests}

The authors declare that they have no competing interests.

\section{References}

1. World Health Organization. Midwifery educator core competencies adaptation tool [Internet]. Geneva, Switzerland; 2014. Available from: https://www.who.int/... midwifery/13012WHO_Midwifery_educator_core_competencies.pdf.Accessed 5 February 2019

2. Baker K. "Senior nursing students perception of clinical teacher behavior"(2012). Nursing Theses and Capstone Projects. 95. [Internet]. Available from: https://digitalcommons.gardnerwebb.edu/nursing_etd/95. Accessec17 January 2019

3. Sezer H. How should clinical education be in nursing education? J Nurs Res Pr. 2018;2(1):15.

4. Weldu M, Gedamu A. Perception of midwifery students towards characteristics of clinical teachers at public Universities, Tigray, Ethiopia, 2016. J Women ' s Heal Care. 2018;7(4):1-6.

5. Martin E, Gumabay D. Caring behaviors of clinical instructors during nursing students' related learning experience: A basis for enhancing student-mentor relationship. Asia Pacific J Multidiscip Res. 2017;5(1):84-93.

6. Kikukawa M, Stalmeijer R, Emura S, Roff S, Scherpbier A. An instrument for evaluating clinical teaching in Japan: content validity and cultural sensitivity. BMC Med Educ. 2014;14(179):1-8.

7. Magnier K, Dale V. Challenges and responsibilities of clinical teachers in the workplace: An ethnographic approach. JVME. 2014;41(2):155-61.

8. Gaberson K, Oermann M, Shellenbarger T. Clinical teaching strategies in nursing [Internet]. fourth edi. Zuccarini M, editor. New York: springer publishing company; 2015. Available from: www.repository.embuni.ac.ke/.../Clinical Teaching Strategies in Nursing. Accessed 5 April 2019

9. Madhavanprabhakaran G, Shukri R, Hayudini J, Narayanan S. Undergraduate nursing students' perception of effective clinical instructor: Oman. Int J Nurs Sci. 2013;3(2):38-44. 
10. Federal Ministry of Education. The Federal Democratic Republic of Ethiopia. Education Sector Development Programme V ( ESDP V) 2015/16-2019/2020 [Internet]. Addis Ababa; 2015. Available from: https://planipolis.iiep.unesco.org/sites/planipolis/files/ressources/ethiopia_esdp_v.pdf. Accessed 17 January 2019

11. Federal Ministry of Education. The Federal Democratic Republic of Ethiopia. List of Ethiopian Public Universities [Internet]. 2013. Available from: https://photos.state.gov/.../ethiopia/.../List of Ethiopian Public Universities

12. FDRE. Universities intake capacity for 2011 Ethiopian calender academic year [Internet]. Addis Ababa: Ethiopian Federal ministry of education; 2018. Available from: http://www.neaea.gov.et/wpcontent/uploads/2018/09/Intake-Capacity-for-2011-Entry.pdf. Accessed 10 February 2019

13. Yigzaw T, Ayalew F, Kim Y, Gelagay M, Dejene D, Gibson H, et al. How well does pre-service education prepare midwives for practice: competence assessment of midwifery students at the point of graduation in Ethiopia. BMC Med Educ. 2015;15(130):1-10.

14. Kube M. The relationship of nursing faculty clinical teaching behaviors to student learning [Internet]. College of Saint Mary; 2010. Available from: https://eric.ed.gov/?id = ED515024. Accessed 17 January 2019

15. Fikre R. Assessment of Factors Affecting Clinical Practice Competency of Undergraduate Health Science Students in Hawassa University,. J Heal Med Nurs. 2016;22(2422-8419):11-8.

16. Reising D, James B, Morse B. Student perceptions of clinical instructor characteristics affecting clinical experiences. Natl Leag Nursing. 2018;39(1):4-9.

17. Mohd Z. The need for in- service training for teachers and it 's effectiveness in school. Int $J$ Innov Educ Res. 2014;2(11):1-9.

18. Firoozehchian F, Taheri Z, Dadgaran I. Nursing-Midwifery students and teachers' views of effective factors in clinical education. Procedia - Soc Behav Sci. 2012;47:1832-7.

19. King J. The impact of teacher experience examining the evidence and policy implications [Internet]. 2010. Available from: https://eric.ed.gov/?id = ED511988\%0A. Accessed 31 May 2019

20. Bharj K, Cert I, Embo M. Factors affecting quality of midwifery student learning in the workplace: results of two ICM congress workshops. Midwifery. 2018;62:116-8.

21. Jimma University. Jimma University revised senate legislation: focusing on academic and technical staff development, roles and responsibilities. Jimma, Ethiopia: Jimma University; 2018.

22. Tamrat A. Educational processes and practices of undergraduate midwifery clinical teaching in Mekelle University [Internet]. Addis Ababa University; 2018. Available from: http://etd.aau.edu.et/bitstream/handle/123456789/13492/Azeb Tamrat.pdf? Accessed 12 April 2019

23. Harackiewicz J, Hulleman C. The importance of interest: The role of achievement goals and task values in promoting the development of interest. Soc Personal Psychol Compass. 2010;4(1):42-52. 